\title{
Response to letter by Drs. Bottinger and van der Hoorn
}

\author{
David A. Berlin ${ }^{1}$, Seth Manoach ${ }^{1}$ and Paul M. Heerdt ${ }^{2}$
}

\author{
* Correspondence: \\ paul.heerdt@yale.edu \\ ${ }^{2}$ Division of Applied Hemodnamics, \\ Yale University School of Medicine, \\ New Haven, USA \\ Full list of author information is \\ available at the end of the article
}

We thank Drs. Bottinger and van der Hoorn for their close reading of our manuscript and their comments. As they point out, our study was designed to primarily evaluate how the relatively unique capability of expiratory ventilatory assistance (EVA) to generate negative end-expiratory pressure (NEEP) affected blood pressure and cardiac output flow in the setting of profound hemorrhage. For the study, after removing 40 $\mathrm{mL} / \mathrm{kg}$ of blood to induce marked hypotension, subjects received either conventional positive pressure ventilation with 0 end-expiratory pressure or EVA ventilation with NEEP. Minute ventilation was matched for both groups and under these conditions, arterial $\mathrm{CO} 2$ was higher in the group receiving EVA ventilation. This difference needs to be interpreted in the context of two very important considerations.

First, the study was designed to assess potential hemodynamic benefits of EVA with NEEP not necessarily optimize ventilation. With NEEP of $-8 \mathrm{cmH} 2 \mathrm{O}$, EVA required a peak inspiratory pressure of only $\sim 6-7 \mathrm{cmH} 20$ to produce a tidal volume and $\mathrm{PaO} 2$ similar to that generated by conventional ventilation with 0 end-expiratory pressure and a peak inspiratory pressure of $20 \mathrm{cmH} 20$. The ability to ventilate with this low PIP is remarkable and clearly contributed to the observed hemodynamic benefit. It also suggests that during hemorrhagic shock, increased gas flow and higher PIP can be used at least intermittently in conjunction with NEEP without major loss of hemodynamic benefit. Ultimately, we agree with Drs. Bottinger and van der Hoorn that broad interpretation of our results in terms of $\mathrm{CO} 2$ removal is not warranted given the specific use of EVA with NEEP and conditions of our experimental protocol. We also agree that the experimental model is not indicative of the established clinical use of EVA rescue ventilation with an obstructed airway and that choice of the catheter and mode of ventilation could have affected the observed efficiency of gas exchange.

Second, study results indicate that the improvements in blood pressure and flow, in conjunction with maintenance of oxygenation, during EVA with NEEP outweigh any decrement in $\mathrm{CO} 2$ elimination with a fixed minute ventilation. In the absence of fluid administration or other resuscitative measures, $1 \mathrm{~h}$ after marked hemorrhage mean arterial pressure was double that in subjects with conventional ventilation and cardiac output nearly $60 \%$ higher. This relatively profound response may have particular short-term benefit in a clinical setting where it is highly likely that volume resuscitation will be implemented sooner and ventilation can be adjusted based upon blood gas analysis.

(c) The Author(s). 2019 Open Access This article is distributed under the terms of the Creative Commons Attribution 4.0 International License (http://creativecommons.org/licenses/by/4.0/), which permits unrestricted use, distribution, and reproduction in any medium, provided you give appropriate credit to the original author(s) and the source, provide a link to the Creative Commons license, and indicate if changes were made. 
Acknowledgements

Not applicable

\section{Authors' contributions}

$\mathrm{PH}$ designed and performed the experiments and supervised all aspects of the study and preparation of the manuscript. SM and DB assisted in the design of the study and the preparation of the manuscript. All authors read and approved the final manuscript.

\section{Funding}

This study was funded in part by a sponsored research agreement (PMH) with Ventinova, BV, Eindhoven, NL. The sponsor had no role in the interpretation of the results or preparation of the manuscript.

\section{Availability of data and materials}

All raw data will be made available in the appendix

\section{Ethics approval and consent to participate}

Institutional Animal Care and Use Committee of Weill Cornell Medicine approved this protocol. Consent was not required as there is no human data.

\section{Consent for publication}

Not applicable

\section{Competing interests}

Dr. Heerdt entered into a sponsored research agreement with Ventinova, BV, Eindhoven NL. The other authors declare that they have no competing interests.

\section{Author details}

${ }^{1}$ Division of Pulmonary and Critical Care Medicine, Weill Cornell Medicine, 1300 York Avenue, New York, NY 10065,

USA. ${ }^{2}$ Division of Applied Hemodnamics, Yale University School of Medicine, New Haven, USA.

Received: 16 May 2019 Accepted: 22 May 2019

Published online: 06 June 2019

\section{Publisher's Note}

Springer Nature remains neutral with regard to jurisdictional claims in published maps and institutional affiliations.

\section{Submit your manuscript to a SpringerOpen ${ }^{\circ}$ journal and benefit from:}

- Convenient online submission

- Rigorous peer review

- Open access: articles freely available online

- High visibility within the field

- Retaining the copyright to your article 